\title{
Teknologi Milenial (Minapadi Legowo Dengan Ikan Lokal) Secara Berkelanjutan di Kecamatan Beutong Nagan Raya
}

\author{
Mahendra, Fazril Saputra, Citra Dina Febrina, Dini Islama \\ Progaram studi Akuakultur, Fakultas Perikanan dan Ilmu Kelautan, Universitas Teuku Umar \\ J1. Alue Peunyareng, Meureubo, Aceh Barat, Provinsi Aceh, Indonesia, \\ Email: mahendra@utu.ac.id
}

\begin{abstract}
Abstrak
Tujuan Pengabdian Berbasis Riset Universitas Teuku Umar ini adalah untuk mengaplikasikan hasil penelitian riset tim pengusul untuk pemberdayaan masyarakat di Kecamatan Beutong, Nagan Raya. Penerapan hasil riset dilakukan pada program kegiatan Teknologi milenial (Minapadi legowo dengan ikan lokal) yang merupakan sistem menanam padi dengan budidaya ikan di dalam satu areal persawahan secara bersamaan. Teknologi ini bertujuan untuk meningkatkan pendapatan hasil petani dengan produktifitas hasil padi yang tinggi dan meningkatkan produksi ikan lokal. Kegiatan dilakukan selama 5 bulan bertempat di Kecamatan Beutong Nagan Raya. Hasil yang diamati meliputi produksi padi dan produksi ikan pada sistem minapadi. Produksi padi tanam legowo $2: 1$ memberikan pengaruh nyata terhadap parameter hasil produksi padi (ton ha' ${ }^{-1}$ ) yaitu (3.04 ton $\mathrm{ha}^{-1}$ ). Sedangkan bobot ikan/petak sebesar (242.25 g) dan tingkat kelangsungan hidup ikan /petak yaitu (65.27\%).
\end{abstract}

Kata kunci: ikan lokal, legowo, minapadi

\section{PENDAHULUAN}

Usaha-usaha pembudidaya ikan selaku pengusaha mikro di Kabupaten Nagan Raya sudah mulai berkembang, namun sayangnya jenis yang dipelihara adalah ikan-ikan asing hasil introduksi dari luar Aceh dan bahkan luar negara. Kondisi ini memberikan tekanan kepada populasi ikan asli setempat. Sementara itu Aceh juga memiliki potensi ikan asli yang tidak kalah baik dari segi jumlah maupun kualitasnya, misalnya ikan serukan (Osteochilus Vittatus), dan udang galah (Macrobracium rosenbergii) (DKP Aceh, 2015). Menurut hasil riset tim peneliti bahwa ikan-ikan lokal yang berhasil ditingkatkan produksinya meliputi ikan serukan (Mahendra dan Supriadi, 2019), udang galah (Mahendra, 2015), udang pisang (Mahendra dan Gazali, 2017) dan ikan gabus lokal (Saputra dan Mahendra, 2018),

Potensi dan peluang usaha bagi calon pengusahan sangat potensial, karena tempat di lokasi kegiatan tersebut sangat strategis, yaitu memiliki sumber air irigasi yang kebutuhannya selalu kontinyu dan rata-rata pekerja sumberdaya manusia di daerah tersebut adalah petani dan pembudidaya ikan, namun kegiatannya hanya mengerjakan satu prioritas saja tanpa intensifikasi untuk meningkatkan pendapatan hasil petani dan pembudidaya ikan.

Kelompok usaha (mitra) akan membuat manajemen usaha khususnya produksi padi dan ikan untuk meningkatkan perekonomian, namun persoalan yang dihadapi mitra adalah belum 
mendapatkan ilmu dan sains yang dapat meningkatkan hasil produksinya. Teknologi milenial ini merupakan sistem menanam padi dengan budidaya ikan di dalam satu areal persawahan secara bersamaan. Teknologi milenial (Minapadi legowo dengan ikan lokal) yang merupakan sistem menanam padi dengan budidaya ikan di dalam satu areal persawahan secara bersamaan. Teknologi ini bertujuan untuk meningkatkan pendapatan hasil petani dengan produktifitas hasil padi yang tinggi dan meningkatkan produksi ikan lokal

Permasalahan prioritas mitra kelompok calon wirausaha baru adalah belum mendapatkan ilmu dan sains yang dapat menjadikan calon pengusaha untuk menjadi pengusahan dengan potensi daerah yang ada. Solusi yang disepakati bersama dalam kegiatan ini adalah memanfaatkan potensi yang ada dengan menerapkan Teknologi milenial (Minapadi legowo dengan ikan lokal) yang merupakan sistem menanam padi dengan budidaya ikan di dalam satu areal persawahan secara bersamaan.

\section{METODE PELAKSANAAN \\ 2.1. Lokasi Kegiatan}

Pelaksanaan kegiatan ini dilakukan di areal persawahan Desa Ujong Blang Kecamatan Beuton Kabupaten Nagan Raya Provinsi Aceh.

\subsection{Bahan dan Alat}

Bahan yang digunakan dalam kegiatan ini adalah: benih padi MAPAN P-05, pupuk urea, pupuk kalium, bibit ikan lokal (seurukan dan udang galah), DMA (obat anti rumput liar), jaring (pagar areal persawahan), pellet dan probiotik. Alat yang digunakan dalam penelitian ini adalah: Hand Traktor, cangkul, ember, timbangan, mistar, parang, tali rapiah, terpal, map plastik, label, meteran, ajir bambu, jaring pengaman, kertas, kamera, dan alat tulis menulis.

\subsection{Metode Pendekatan Yang Ditawarkan Untuk Mitra Calon Wirausaha}

Metode yang ditawarkan adalah dengan menerapkan teknologi milenial (Minapadi legowo dengan ikan lokal) yang merupakan sistem menanam padi dengan budidaya ikan di dalam satu areal persawahan secara bersamaan. Teknologi ini bertujuan untuk meningkatkan pendapatan hasil petani dengan produktifitas hasil padi yang tinggi dan meningkatkan produksi ikan lokal.

\subsection{Prosedur Kegiatan}

Kegiatan teknologi pertama kali dilakukan pengolahan tanah di areal persawahan yang akan dijadikan budidaya ikan sistem minapadi dengan mengunakan hand traktor yang di ulang sebanyak 3 kali untuk menggemburkan tanah dan memudahkan penenaman padi. Selanjutnya Pembentukan kemalir untuk pemeliharaan ikan lokal dengan lebar $50 \mathrm{~cm}$ dan kedalaman $50 \mathrm{~cm}$. Areal perawahan dilakukan pemagaran dengan jaring agar tidak terserang hama dan penyakit pada ikan lokal dan padi. Sebelum dilakukan proses penenaman padi, terlebih dahulu dilakukanPembentukan garis tanam yang lurus dan jelas dengan cara menarik alat garis tanam yang sudah dipersiapkan sebelumnya serta dibantu dengan tali yang dibentang dari ujung ke ujung lahan. Kemudian 
menyiapkan bibit padi yang digunakan merupakan varietas unggul (MAPAN P-05) selama 17 hari. Bibitpadi yang digunakan sebanyak 2 bibit per lubang tanam pada perpotongan garis yang sudah terbentuk. Proses penanaman padi menggunakan sistem tanam padi legowo 4:1 dan 2: 1 yang merupakan hasil terbaik (Bobihoe, 2013) yaitu untuk 4:1 cara tanam padi yang memiliki 4 barisan tanaman kemudian diselingi oleh 1 baris kosong dimana jarak tanam adalah $25 \mathrm{~cm}$. Proses penebaran ikan lokal (ikan seurukan dan udang galah) dilakukan setiap petakan per jenis dengan padat tebar 500 ekor/petakan setelah 30 hari penanaman padi dilakukan. Memberikan pakan pellet jenis F-999 (ikan seurukan) dan gold coin (udang galah secara ad-libitum dengan frekuensi $2 \mathrm{x}$ sehari. Pemanenan dilakukan ketika 90\% gabah menguning atau dilakukan 10 hari sebelum panen padi dengan cara mengeringkan petakan sawah terlebih dahulu kemudian ikan ditangkap secara perlahan-lahan dengan cara menyeser ikan dan udang secara total.

\section{HASIL DAN PeEMBAHASAN}

\subsection{Kondisi Umum Daerah Pengabdian}

Pertanian merupakan usaha pengelohan untuk pembudidayaan tanaman pangan. Masyarakat agraris mengandalkan sektor pertanian sebagai mata pencaharian utamanya. Persawahan merupakan pertanian tetap (tidak berpindah) yang menggunakan lahan basah yang diairi secara teratur. Tanaman yang biasanya ditanam pada persawahan adalah padi.

Dilihat secara garis besar mata pencaharian masyarakat Beutong adalah petani, dengan lahan yang sangat luas sehingga memudahkan bagi masyarakat setempat untuk bercocok tanam, hal tersebut juga diuntungkan dengan adanya proses irigasi yang sangan memadai sehingga menghasilkan produksi panen padi yang cukup tinggi. Data tersebut dapat dilihat pada Tabel 1, 2, dan 3 dibawah ini:

Tabel 1. Pengairan irigasi di Kecamatan Beutong Nagan Raya

\begin{tabular}{rlrcr}
\hline \multicolumn{1}{c}{$\begin{array}{c}\text { Kecamatan } \\
\text { Subdistrict }\end{array}$} & $\begin{array}{c}\text { Irigasi } \\
\text { Irrigation }\end{array}$ & $\begin{array}{c}\text { Non Irigasi } \\
\text { Non Irrigation }\end{array}$ & $\begin{array}{c}\text { Jumlah } \\
\text { Total }\end{array}$ \\
\hline \multicolumn{1}{c}{$(1)$} & \multicolumn{1}{c}{$(2)$} & \multicolumn{1}{c}{$(3)$} & \multicolumn{1}{c}{$(4)$} \\
\hline 1 & Darul Makmur & 64,0 & 740,0 & 804,0 \\
2 & Tripa Makmur & 60,0 & 391,0 & 451,0 \\
3 & Kuala & 1179,0 & 482,0 & 1661,0 \\
4 & Kuala Pesisir & 200,0 & 271,0 & 471,0 \\
5 & Tadu raya & 80,0 & 358,0 & 438,0 \\
6 & Beutong & 3001,0 & 324,0 & 3325,0 \\
7 & Beutong Ateuh Banggalang & 395,0 & 174,0 & 569,0 \\
8 & Seunagan & 2031,0 & 315,0 & 2346,0 \\
9 & Suka Makmue & 2349,0 & 302,0 & 2651,0 \\
10 & Seunagan Timur & 3284,0 & 300,0 & 3584,0 \\
\hline & Nagan Raya & 12643,0 & $\mathbf{3 6 5 7 , 0}$ & $16 \mathbf{3 0 0 , 0}$
\end{tabular}

Sumber: BPS Nagan Raya (2017) 
Data di atas menunjukkan bahwa Kecamatan Beutong merupakan Kecamatan yang memiliki sistem perairan irigasi yang luas atau besar untuk proses perairan di areal persawahan yaitu sebesar 3001 ha, yang merupakan terbesar kedua setelah Kecamatan Seunagan Timur. Potensi yang besar tersebut hanya dimanfaatkan untuk produksi padi (tunggal) saja tanpa integrasi jenis lain, sehingga penerapan proses budidaya ikan (lokal) sangat tepat di daerah tersebut yang dapat meningkatkan pendapatan petani setempat. Hal ini dapat dilihat pada Tabel 5 yang mana penggunaan budidaya ikan dengan sistem minapadi model legowo dapat meningkatkan pendapatan petani.

Tabel 2. Hasil panen padi sawah di Kecamatan Beutong Nagan Raya

\begin{tabular}{|l|c|c|}
\hline \multirow{2}{*}{ Jenis Tanaman } & \multicolumn{2}{|c|}{ Luas (Ha) } \\
\cline { 2 - 3 } 1. Padi Sawah & Tanam & Panen \\
\hline (1) & 5085 & (3) \\
\hline 2. Kedelai & 0 & 2189,1 \\
\hline 3. Jagung & 39 & 58 \\
\hline 4. Kacang Tanah & 8 & 6 \\
\hline 5. Kacang Hijau & 0 & 0 \\
\hline 6. Ubi Kayu & 3 & 5 \\
\hline 7. Ubi Jalar & & \\
\hline
\end{tabular}

Sumber: BPS Nagan Raya (2017)

Tabel 2, tentang hasil panen padi sawah menunjukkan bahwa sebagian besar mata pencaharian masyarakat Beutong adalah petani yang monospesies (padi) dilihat dari data diatas yaitu dengan hasil panen 6189 ha yang terbesar jenis tanaman padi dibandingkan dengan tanaman lain. Hal yang sangat tepat dilakukan program pengabdian di Kecamatan Beutong untuk meningkatkan pendapatan petani dengan menerapkan lebih dari satu jenis yaitu padi dan ikan lokal dengan sistem budidaya ikan pada minapadi.

Hasil luas lahan sawah pada Tabel 3, menunjukkan bahwa Kecamatan Beutong merupakan Kecamatan dengan luas lahan sawah terbesar kedua setelah Seunagan Timur yaitu sebesar 5571 ha. Hal ini menunjukkan bahwa Kecamata Beutong memiliki potensi yang sangat besar untuk menerapkan sistem minapadi untuk budidaya ikan dan padi, sehingga dapat meningkatkan pendapatan petani setempat.

Hasil kegiatan ini sangat tepat dilakukan di Kecamatan Beutong dengan menerapkan budidaya ikan lokal dengan sistem minapadi, hal ini dikarenakan di daerah tersebut belum pernah 
menerapkan sistem minapadi, sehingga petani dapat meningkatkan pendapatannya dan juga menjadikan desa percontohan untuk menerapkan model tersebut ke desa lain yang memiliki potensi yang sama. Data perikanan di daerah Beutong (Tabel 4) menunjukkan bahwa hasil budidaya ikan sangat kecil bahkan belum ada dibudidayakan di dalam kolam apalagi di areal persawahan (minapadi). Sehingga kagiatan ini sangat khasanah untuk petani daerah setempat dan juga se-Nagan Raya.

Tabel 3. Luas lahan sawah di Kecamatan Beutong Nagan Raya

\begin{tabular}{llrr}
\hline & \multicolumn{1}{c}{$\begin{array}{c}\text { Kecamatan } \\
\text { Subdistrict }\end{array}$} & $\begin{array}{c}\text { Lahan Sawah } \\
\text { Paddy Land }\end{array}$ & $\begin{array}{c}\text { Lahan bukan Sawah } \\
\text { Non Paddy Land }\end{array}$ \\
\hline \multicolumn{1}{c}{$(1)$} & \multicolumn{1}{c}{$(2)$} & \\
\hline 1 & Darul Makmur & 876,2 & 0,0 \\
2 & Tripa Makmur & 428,0 & 146,0 \\
3 & Kuala & 2590,1 & 112,0 \\
4 & Kuala Pesisir & 536,7 & 0,0 \\
5 & Tadu raya & 713,6 & 5,0 \\
6 & Beutong & 5571,0 & 99,0 \\
7 & Beutong Ateuh Banggalang & 380,0 & 0,0 \\
8 & Seunagan & 3902,2 & 109,0 \\
9 & Suka Makmue & 4533,9 & 102,0 \\
10 & Seunagan Timur & 6009,3 & 63,0 \\
\hline & Nagan Raya & $\mathbf{2 5} 541,0$ & 636,0 \\
\hline
\end{tabular}

Sumber: BPS Nagan Raya (2017)

Tabel 4. Pemanfaatan perikanan di Kecamatan Beutong Nagan Raya 


\begin{tabular}{|c|c|c|c|c|}
\hline & $\begin{array}{l}\text { Kecamatan } \\
\text { Subdistrict }\end{array}$ & $\begin{array}{c}\text { Perikanan Laut } \\
\text { Marine } \\
\text { Fisheries } \\
\end{array}$ & $\begin{array}{l}\text { Perairan } \\
\text { Umum } \\
\text { Inland Woter }\end{array}$ & $\begin{array}{l}\text { Jumlah } \\
\text { Total }\end{array}$ \\
\hline \multicolumn{2}{|r|}{ (1) } & (2) & (3) & (4) \\
\hline 1 & Darul Makmur & 14,35 & 136,65 & 151,00 \\
\hline 2 & Tripa Makmur & 65,50 & 135,20 & 200,70 \\
\hline 3 & Kuala & - & 58,25 & 58,25 \\
\hline 4 & Kuala Pesisir & 824,40 & 73,81 & 898,21 \\
\hline 5 & Tadu Raya & 249,40 & 136,50 & 385,90 \\
\hline 6 & Beutong & - & 46,24 & 46,24 \\
\hline 7 & $\begin{array}{l}\text { Beutong Ateuh } \\
\text { Banggalang }\end{array}$ & & 21,36 & 21,36 \\
\hline 8 & Seunagan & - & 74,68 & 74,68 \\
\hline 9 & Suka Makmue & - & 91,23 & 91,23 \\
\hline 10 & Seunagan Timur & - & 40,03 & 40,03 \\
\hline & Nagan Raya & 1153,65 & 813,95 & 1967,60 \\
\hline
\end{tabular}

Sumber: BPS Nagan Raya (2017)

\subsection{Proses Budidaya Ikan Lokal Sistem Minapadi Legowo}

Proses budidaya ikan lokal (ikan seurukan dan udang galah) di areal persawahan yang akan dijadikan budidaya ikan sistem minapadi sebaiknya dilakukan pada areal persawahan dengan debit air selalu ada sepanjang waktu atau menggunakan irigasi. Lokasi yang digunakan sesuai dengan syarat budidaya ikan sistem minapadi, di lokasi kegiatan memiliki luas areal irigasi yang memadai (Tabel 1) penggunaan irigasi pada sistem minapadi, selain untuk mengairi sawah juga untuk pemeliharan ikan dan udang dan juga kualitas air yang terbaru akan menjadikan pertumbuhan ikan yang sangat baik. Hal ini sesuai dengan pendapat Sudiarta et al., (2016) yang menyatakan bahwa model minapadi cukup efisien dan efektif untuk diterapkan pada sawah irigasi yang ketersediaan airnya selalu ada untuk pertumbuhan padi dan ikan. Irigasi model minapadi di lokasi kegiatan dapat di lihat pada Gambar 1, di bawah ini.

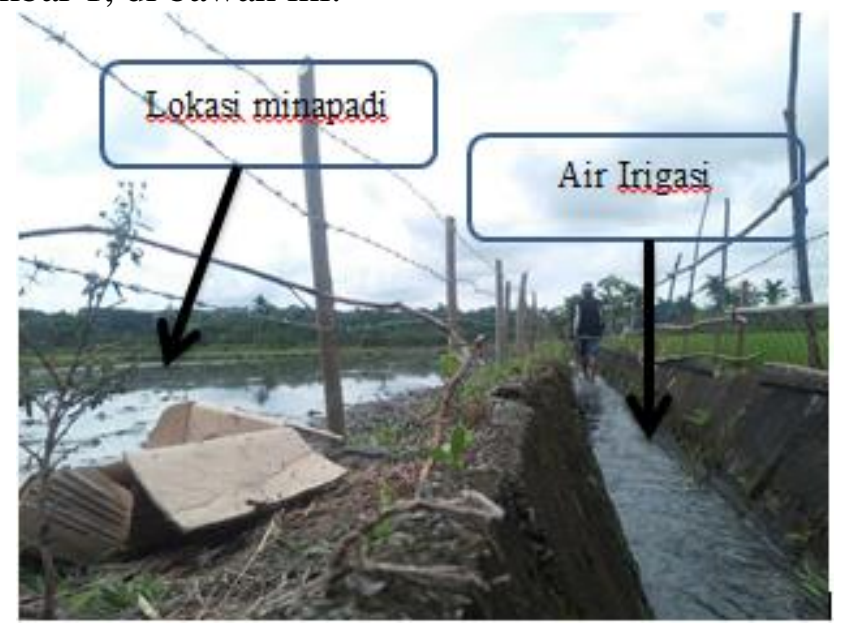


Gambar 1. Irigasi dilokasi kegiatan

Syarat lokasi yang baik untuk minapadi tersebut kemudian dijadikan areal persawahan minapadi percontohan. Sawah yang digunakan dengan luas per petak adalah 5 x $11 \mathrm{~m}^{2}$ sebagai percontohan. Sebelum memulai kegiatan, terlebih dahulu dilakukan penggemburan tanah dengan menggunakan hand traktor. Hal ini bertujuan untuk menguapkan gas beracun dan juga unsur hara di dalam tanah lebih subur serta untuk memudahkan bercocok tanam padi. Kegiatan hand traktor sawah ini dilakukan sebanyak 3 kali dalam keadaan basah/lembab/kondisi berair. Penggemburan tanah dilokasi kegiatan dengan hand traktor dapat dilihat pada Gambar 2. Tujuan pengolahan tanah menurut Nurhayati et al., (2015) menyatakan bahwa pengolahan tanah dalam minapadi berfungsi ganda yaitu untuk persiapan tumbuhnya padi, juga menumbuhkan mikroorganisme sebagai makanan ikan.

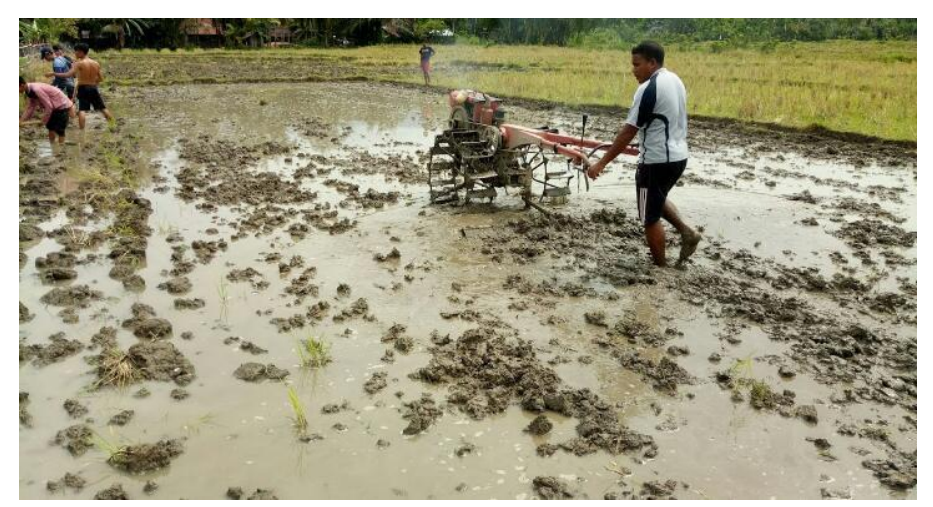

Gambar 2. Pengolahan tanah dengan hand traktor

Selain pengolahan tanah sawah dengan hand traktor, dilakukan juga membuat kemalir dengan menggunakan cangkul (Gambar 3). Hal ini bertujuan selain untuk wadah pemeliharaan ikan agar terhindar dari panasnya matahari secara langsung, juga untuk mengatasi hama berupa keong serta untuk memudahkan pada saat pemanenan ikan. Menurut Hadi dan Astuti, (2013) tujuan kemalir adalah melindungi ikan dari serangan hama serta bahaya kekeringan yang disebabkan oleh penguapan yang tinggi. Selokan atau kemalir ini dibuat melintang/horizontaldan sejajar pematang dengan lebar 1 meter serta kedalaman 50-70 cm. Pembentukan kemalir untuk pemeliharaan ikan lokal dengan lebar $50 \mathrm{~cm}$ dan kedalaman $50 \mathrm{~cm}$
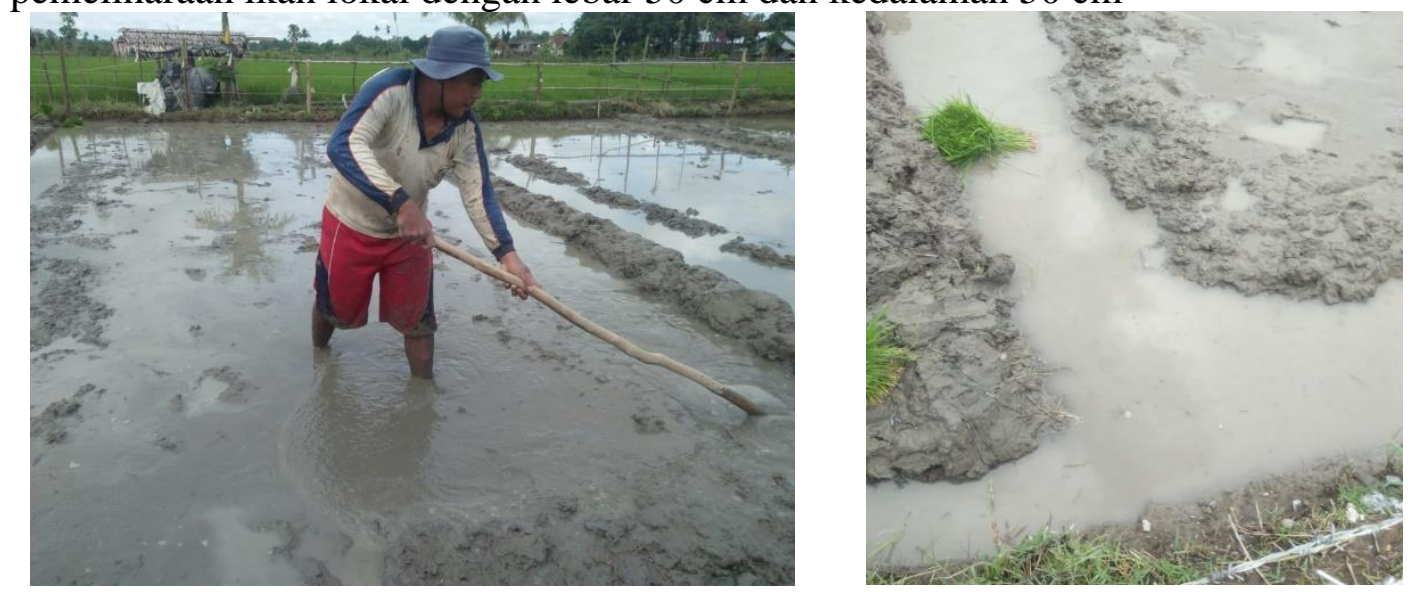
Gambar 3. Pembuatan kemalir dengan cangkul

Areal persawahan dilakukan pemagaran dengan jaring agar tidak terserang hama dan penyakit pada ikan lokal dan padi. Pemasangan jaring dilakukan pada tepi atau sekitar sawah (pagar) dan juga pada atas padi untuk menghindari serangan hama berupa burung. Pemasangan jaring diatas padi dilakukan pada saat padi sudah berbuah.
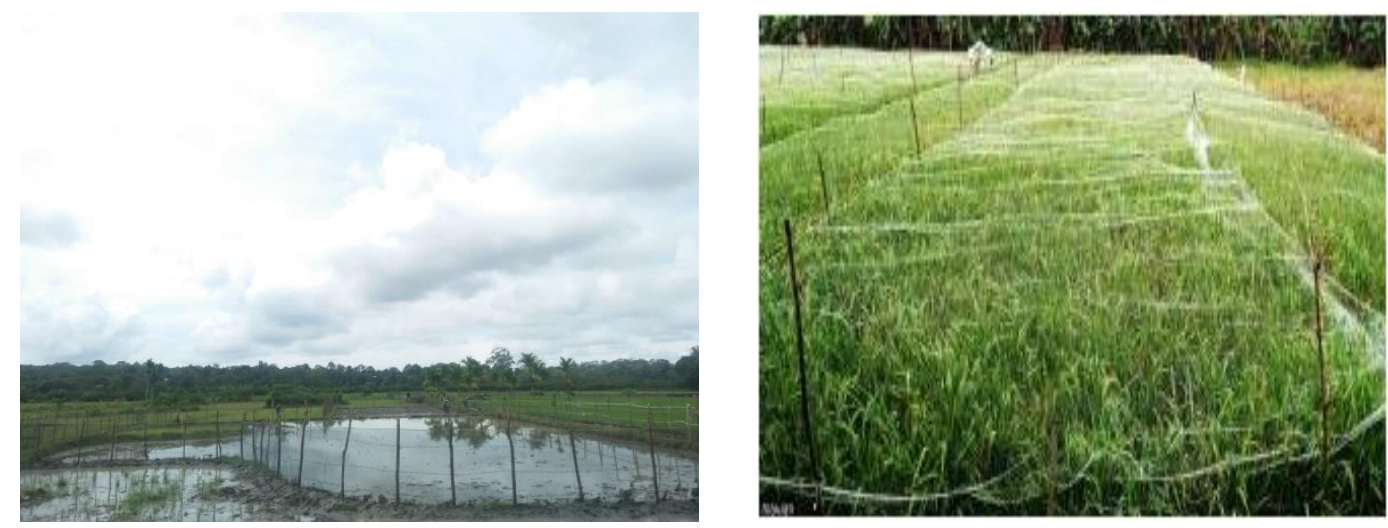

Gambar 4. Pemagaran menggunakan jaring pada tepi dan atas areal padi sawah

Menurut Hadi dan Astuti, (2013) hama yang menyerang padi dan ikan adalah burung, ular atau musang air/berang-berang dan keong mas (Hidayat, 2018). Hama selain merusak/memakan/pesaing juga pembawa penyakin/agen bagi kehidupan ikan. Sehingga dilakukan pemagaran baik di samping maupun di atas.

Selanjutnya sebelum dilakukan proses penanaman padi, terlebih dahulu dilakukan pembentukan garis tanam (legowo) yang lurus dan jelas dengan cara menarik alat garis tanam yang sudah dipersiapkan sebelumnya (Gambar 5) serta dibantu dengan tali yang dibentang dari ujung ke ujung lahan.

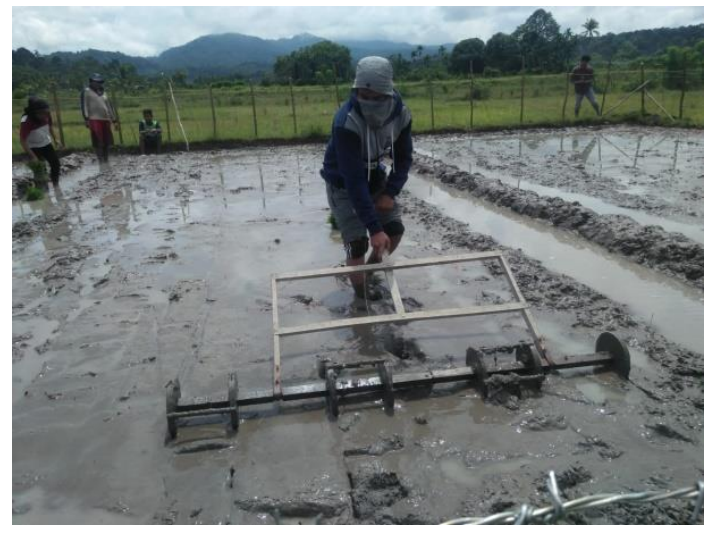

Gambar 5. Pembentukan garis tanam (legowo) dengan alat pengerik garis tanam 
Bibit padi yang digunakan merupakan varietas unggul jenis MAPAN P-05 (Gambar 6, kiri) yang disemai selama 18 hari (Hidayat, 2018). Bibit padi yang digunakan sebanyak 2 batang per lubang tanam pada perpotongan garis yang sudah terbentuk. Proses penanaman padi menggunakan sistem tanam padi legowo 4:1 dan 2: 1 yang merupakan hasil terbaik (Bobihoe, 2013) yaitu untuk 4:1 cara tanam padi yang memiliki 4 barisan tanaman kemudian diselingi oleh 1 baris kosong setiap petak dimana jarak tanam adalah $25 \mathrm{~cm}$. proses tanam padi legowo 2:1 dan 4:1 dapat dilihat pada Gambar 7.
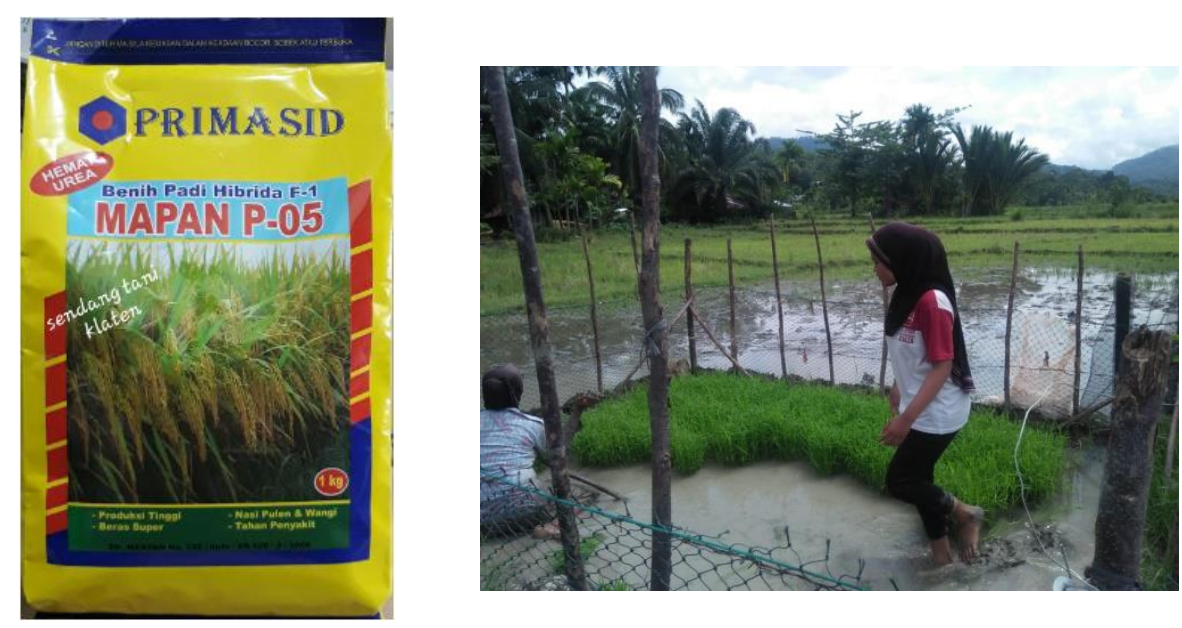

Gambar 6. Benih padi komersial (kiri) dan bibit padi yang disemai (kanan)
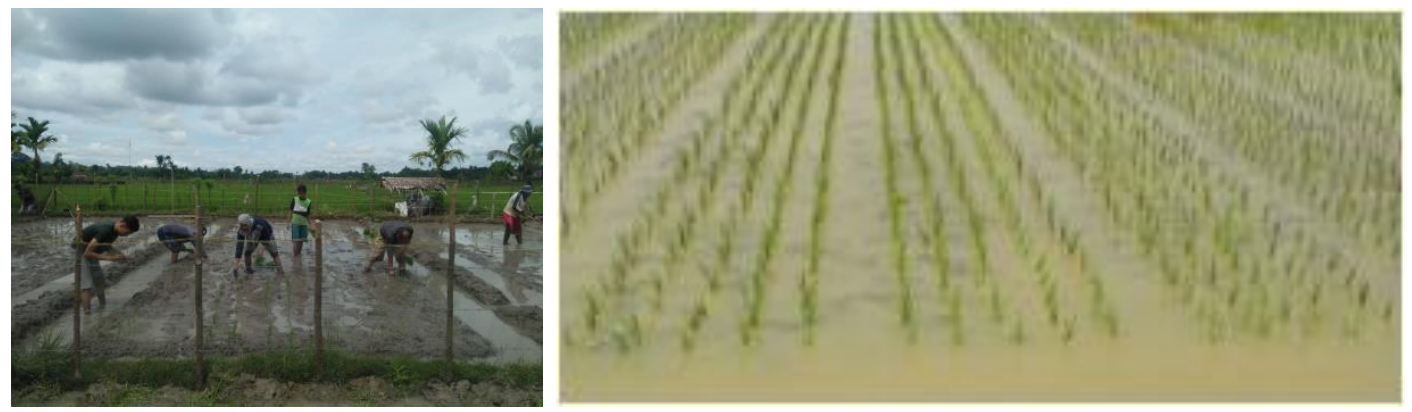

Gambar 7. Proses tanam padi sistem legowo 
Proses penebaran ikan lokal (ikan seurukan dan udang galah) dilakukan setiap petakan per jenis dengan padat tebar 500 ekor/petakan setelah 30 hari penanaman padi dilakukan. Menurut BPTP Sulawesi Barat, (2016) penebaran benih ikan dilakukan 30 hari setelah penanaman padi dengan tujuan untuk menghindari obat-obatan atau pupuk. Penebaran benih ikan dilakukan pada sore hari secara perlahan-lahan agar ikan tidak mengalami stress akibat perubahan lingkungan.

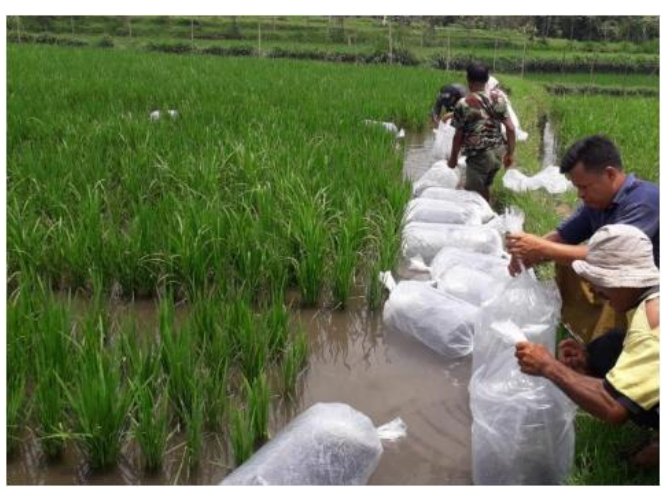

Gambar 8. Penebaran ikan dan udang galah

Pemberian pakan pellet jenis F-999 (ikan seurukan) dan gold coin (udang galah) secara adlibitum dengan frekuensi 2 x sehari.
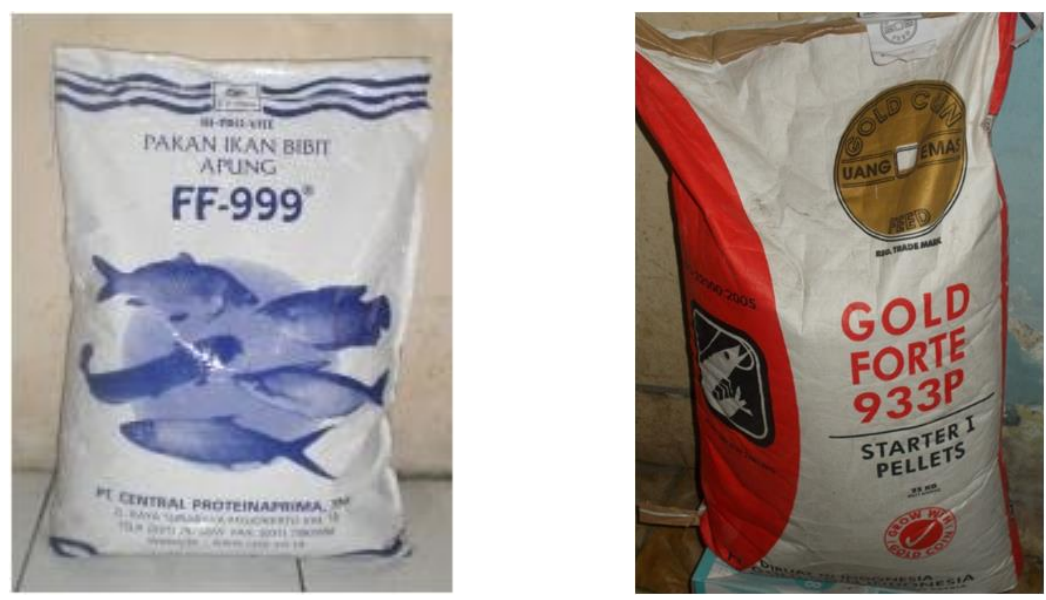
Gambar 9. Pellet ikan seurukan (FF-999) dan pellet udang galag (Gold Coin)

Pemanenan dilakukan ketika 90\% gabah menguning atau dilakukan 10 hari sebelum panen padi dengan cara mengeringkan petakan sawah terlebih dahulu kemudian ikan ditangkap secara perlahan-lahan dengan cara menyeser ikan dan udang secara total

\subsection{Produksi Padi Dan Ikan}

Hasil produksi padi dengan system minapadi legowo dapat dilihat pada Tabel dibawah ini:

Tabel 5. Hasil produksi padi sistem minapadi legowo

\begin{tabular}{lcccc}
\hline \multicolumn{1}{c}{ Model } & $\begin{array}{c}\text { Produksi Padi } \\
\text { (Sudiarta } \text { et al. },\end{array}$ & satuan & $\begin{array}{c}\text { Produksi Padi } \\
\text { (data diolah) }\end{array}$ & Satuan \\
\hline Tanpa legowo & $2.39^{\mathrm{a}}$ & ton/ha & 13.15 & $\mathrm{Kg} / \mathrm{ha}^{\mathrm{a}}$ \\
Legowo 2:1 & $3.04^{\mathrm{b}}$ & ton/ha & 16.72 & $\mathrm{Kg} / \mathrm{ha}^{\mathrm{b}}$ \\
Legowo 4:1 & $2.94^{\mathrm{b}}$ & ton/ha & 16.17 & $\mathrm{Kg} / \mathrm{ha}^{\mathrm{b}}$ \\
\hline
\end{tabular}

Keterangan : Angka-angka yang diikuti oleh huruf yang tidak sama berarti berbeda nyata pada taraf nyata $5 \%$ berdasarkan uji BNT

Menurut Sudiarta et al., (2016) rata-rata produksi padi (ton ha-1) berdasarkan uji BNT menunjukan bahwa perlakuan legowo $2: 1$ memberikan hasil tertinggi bila dibandingkan dengan perlakuan lainnya dengan rata-rata produksi padi sebesar $(3.04$ ton/ha), dan tidak berbeda nyata dengan perlakuan legowo $4: 1$ sebesar (2.94 ton/ha) namun berbeda nyata dengan perlakuan tanpa legowo sebesar (2.39 ton $\left./ \mathrm{ha}^{-1}\right)$.

Sedangkan kepadatan populasi ikan 24 ekor/petak memberikan pengaruh nyata terhadap bobot ikan/petak sebesar (242.25 g) dan tingkat kelangsungan hidup ikan, serta bobot ikan/ekor dihasilkan oleh padat penebaran 12 ekor/petak yaitu (65.27 \%), bobot ikan/ekor sebesar (18.79 g) (Sudiarta et al., 2016).

\subsection{Analisis $R / C$ dan $B / C$ Rasio}

Analisis usaha tani sistem minapadi bagi petani perlu dilakukan untuk mengetahui seberapa besar nilai tambah yang bisa di peroleh dari usaha tersebut, maka analisis ekonomi sebagai bagian untuk mengetahui apakah sistem tersebut layak atau tidak di kembangkan dan untuk mengetahui sistem minapadi memberikan keuntungan atau tidak. Maka dibawah ini diuraikan secara sederhana analisis usaha tani sistem minapadi yang diterapkan dengan satu kali usaha dalam satu musim tanam.

Menurut Sudiarta et al., (2016) Analisis usaha tani sistem minapadi menunjukan bahwa total biaya yang dikeluarkan dalam satu musim tanam sebesar Rp.9.715.000 dan total pendapatan yang diperoleh sebesar Rp.20.277.500, sehingga diperoleh keuntungan dari sistem minapadi sebesar Rp.10.562.500. Dengan demikian sistem minapadi layak untung dikembangkan karena nilai R/C 
rasionya 2,08 yang berarti usaha tani sudah efisien karena nilai $\mathrm{R} / \mathrm{C}$ rasionya sudah lebih dari satu, demikian pula nilai $\mathrm{B} / \mathrm{C}$ rasionya yang lebih dari satu yakni 1.08. Keuntungan bersih yang diperoleh setelah dikurangi total biaya adalah sebesar Rp.10.562.500. Menurut Akbar (2017) keuntungan yang diperoleh petani sebelum diterapkan sistem mina padi yaitu sebesar Rp. 46.589.495/tahun setelah petani menerapkan sistem Mina Padi, keuntungan petani meningkat sebesar Rp.75.401.269/ha/tahun.

Keuntungan yang didapat oleh petani dari sistem minapadi (Akbar,2017) :

1) Meningkatkan pendapatan petani padi sawah yang mengalami kegagalan panen akibat hama wereng, karena dengan adanya ikan disawah akan mengonsumsi hama wereng, yang jatuh air akibat gerakan ikan.

2) Membantu mempercepat perbaikan lingkungan karena dengan mina padi akan menguragi gas metan yang dibuang dari sisa pemupukan.

3) Mengemat penggunaan pupuk.

4) Peningkatan konsumsi ikan guna perbaikanj gizi keluarga.

5) Diperoleh dua macam produksi sekaligus sehingga dapat meningkatkan pendapatan petani padi sawah.

6) Petani menjadi lebih rajin mengawasi sawahnya ,karena harus mengecek air yg masuk kesawah dan mengecek saring yg di pasang agar ikan tidak keluar.

7) Memperbaiki struktur tanah, karena ikan dalam mencari makan membolak balik tanah.

8) Meningkatkan potensi lahan sawah yang ada.

9) Dapat menekan pertumbuhan gulma, menguragi serangan hama dan penyakit, dan dapat meningkatkan musuh alami bagi tanaman, dan

10) Kotoran ikan merupakan pupuk organik bagi tanamam padi.

\section{KESIMPULAN DAN SARAN \\ 4.1.Kesimpulan}

Potensi lahan sawah irigasi di Kecamatan Beutong secara teknis memenuhi syarat untuk pengembangan minapadi. Berdasarkan hasil dan pembahasan dapat disimpulkan bahwa sistem tanam jajar legowo 2:1 memberikan pengaruh nyata terhadap parameter hasil produksi padi (ton $\mathrm{ha}^{-1}$ ) yaitu (3.04 ton $\left.\mathrm{ha}^{-1}\right)$. Sedangkan bobot ikan/petak sebesar (242.25 g) dan tingkat kelangsungan hidup ikan/petak yaitu (65.27 \%). Hasil analisis tersebut memberikan keuntungan jika dilakukan budidaya ikan sistem minapadi legowo

\subsection{Saran}

Perlu dilakukan penelitian lebih lanjut tentang sistem tanam jajar legowo pada jarak tanam yang berbeda dengan kepadatan populasi ikan sistem minapadi, terhadap pertumbuhan dan produksi padi dan ikan.

\section{UCAPAN TERIMA KASIH}

Riset penulis dibiayai oleh hibah penelitian internal Universitas Teuku Umar khusunya LPPM dan Penjaminan Mutu serta Program Studi Akuakultur Fakultas Perikanan dan Ilmu Kelautan. 
Jurnal Karya Abdi Masyarakat

p-ISSN:2580-1120

Volume 3 Nomor 2 Desember 2019

e-ISSN:2580-2178

\section{DAFTAR PUSTAKA}

Akbar, A. 2017. Peran Intensifikasi Mina Padi Dalam Menambah Pendapatan Petani Padi Sawah Digampong Gegarang Kecamatan Jagong Jeget Kabupaten Aceh Tengah. Jurnal S. Pertanian 1 (1) : $28-38$

Badan Pusat Statistik Nagan Raya. 2017. Nagan Raya Dalam Angka. Penerbit BPS Kabupaten Nagan Raya. Hal 227

Balai Pengkajian Teknologi Pertanian Sulawesi Barat. 2016. Teknologi Mina Padi dengan Sistim Tanam Jajar Legowo. Balitbangtan Sulawesi Barat . Mamuju

Bobihoe, J. 2013. Sistem Tanam Padi Jajar Legowo. Balai pengkajian teknologi pertanian (BPTP) Jambi. ISBN : 978-602-1276-01-3

Dinas Kelautan dan Perikanan Aceh. 2015. Identifikasi Jenis-Jenis Ikan Endemik Di Perairan Aceh Wilayah Barat Selatan (Aceh Barat). Laporan Akhir. Banda Aceh

Hadi, P dan Astuti, U.P. 2013. Pemeliharaan Ikan Bersama Padi Di Sawah (Mina Padi), Sebuah Potensi Keuntungan Ganda Untuk Petani Di Provinsi Bengkulu. Dinas Pertanian Provinsi Bengkulu

Hidayat, M.N. 2018. Pembesaran Ikan Nila (Oreochromis niloticus) Dengan Sistem Mina Padi Pada Kelompok Ngudi Rejeki, Kec.Tawangsari, Desa Dalangan, Kab.Sukoharjo. Laporan Praktik Integrasi. Program Studi Teknologi Akuakultur Jurusan Teknologi Pengelolaan Sumberdaya Perairan Sekolah Tinggi Perikanan Jakarta

Mahendra dan Gazali, M. 2017. Penambahan Kalium untuk Meningkatkan Kelangsungan Hidup dan Pertumbuhan Juvenil Udang Pisang (Panaeus Spp). Prosiding Simposium Nasional Perikanan Dan Kelautan. Meulaboh

Mahendra dan Supriadi. 2019. Laju Pertumbuhan Larva Ikan Seurukan (Osteochilus vittatus) Dengan Pemberian Kuning Telur Unggas. Jurnal Akuakultura

Mahendra. 2015. Kombinasi Kadar Kalium Dan Salinitas Media Pada Performance Juvenil Udang Galah (Macrobrachium rosenbergii de Man). Jurnal Perikanan Tropis. 2(1): 55-71

Nurhayati, A., Rustikawati, I dan Maulina, I. 2015. Analisis Optimalisasi Minapadi Yang Berkelanjutan (Suatu Kasus di Kecamatan Ciparay Kabupaten Bandung Provinsi Jawa Barat). Fakultas Perikanan dan Ilmu Kelautan,Universitas Padjadjaran

Saputra, F. dan Mahendra, 2018. Pemeliharaan Ikan Gabus Lokal (Channa sp.) Pada Wadah Yang Berbeda Dalam Rangka Domestikasi Di Daerah Arongan Lambalek, Kabupaten Aceh Barat, Provinsi Aceh. Laporan Akhir. Meulaboh

Sudiarta, I.M., Syam'un, E dan Syamsuddin, R. 2016. Pertumbuhan Dan Produksi Tanaman Padi Serta Produksi Ikan Nila Pada Sistem Tanam Jajar Legowo. J. Sains \& Teknologi, 16 (1): $70-80$ 